\title{
Traumatic retinal detachment
}

\author{
P B Johnston
}

\begin{abstract}
Seventy-seven patients developed retinal breaks following an episode of ocular contusion, and $65(84.4 \%)$ of these developed rhegmatogenous retinal detachment. Surgical treatment successfully restored or maintained retinal apposition in $74(96.1 \%)$ of the eyes. Thirty-six (46.8\%) eyes recovered visual acuity of $6 / 9$ or better. Of the retinal breaks recognised dialysis at the ora serrata was observed in 49 eyes, of which 28 were situated at the lower temporal quadrant. Seventeen eyes had irregular breaks arising within necrotic retina at the site of scleral impact. Twenty-four (31.2\%) patients had retinal break or retinal detachment diagnosed within 24 hours of injury and $49(63.6 \%)$ within six weeks. Immediate retinal detachment was a feature of necrotic retinal breaks, while inferior oral dialyses led to a slow accumulation of subretinal fluid. Delayed diagnosis of retinal detachment was due either to opaque media or to failure to examine the retina after injury. Visual prognosis was good when retinal break or detachment were diagnosed within six weeks of injury. However, those patients who escaped initial retinal examination and were lost to follow-up had a less favourable visual outcome.
\end{abstract}

Ophthalmology, Royal Victoria Hospital, Belfast BT12 6BA, Northern Ireland P B Johnston Correspondence to: Mr P B Johnston, FRCS Accepted for publication 19 July 1990

Impact of a blunt object against the eye causes direct tissue damage at the site of impact and indirect injury to distant intraocular tissues by transmitted forces. This type of contusional

Table 1 Cause of injury

\begin{tabular}{lrr}
\hline & $N o$ & $\%$ \\
\hline Missiles & 38 & $49 \cdot 4$ \\
Sport & 23 & $30 \cdot 0$ \\
Assault & 10 & $13 \cdot 0$ \\
RTA & 2 & $2 \cdot 6$ \\
Fall & 3 & $4 \cdot 0$ \\
Explosion & 1 & $1 \cdot 3$ \\
Total & 77 & \\
\hline
\end{tabular}

$\star$ Road traffic accident.

Table 2 Associated ocular injury

\begin{tabular}{lcc}
\hline & $N o$ & $\%$ \\
\hline Vitreous haemorrhage & 40 & 52 \\
Hyphaema & 32 & 42 \\
Lens subluxation & 11 & $\mathbf{1 4 \cdot 2}$ \\
Iridodialysis & 4 & $5 \cdot 2$ \\
\hline
\end{tabular}

Table 3 Types and location of retinal breaks

\begin{tabular}{llllll}
\hline & No & $\begin{array}{l}\text { Upper } \\
\text { temporal }\end{array}$ & $\begin{array}{l}\text { Upper } \\
\text { nasal }\end{array}$ & $\begin{array}{l}\text { Lower } \\
\text { temporal }\end{array}$ & $\begin{array}{l}\text { Lower } \\
\text { nasal }\end{array}$ \\
\hline Ora (dialysis) & 49 & 10 & 10 & 28 & 1 \\
Impact necrosis & 17 & 5 & 0 & 10 & 2 \\
Horseshoe & 7 & 4 & 3 & 0 & 0 \\
Giant tear & 3 & 3 & 3 & & \\
No tear & 1 & & & & \\
Total & 77 & & & & \\
\hline
\end{tabular}

trauma is a well recognised cause of rhegmatogenous retinal detachment, which was reported by Eagling ${ }^{1}$ to affect $4 \cdot 6 \%$ of such injuries. The characteristics of postcontusion retinal detachments were described by Cox et $a l^{2}$ and the mechanism of break formation was elucidated by Delori $e t a l^{3}$ who studied the effect of high speed projectiles on enucleated pig eyes. Experimental evidence indicates that retinal breaks form at the time of ocular impact. However, clinical reports show considerable delay in the diagnosis of post-traumatic retinal detachment. For example, Cox et $a l^{2}$ reported that only $30 \%$ of posttraumatic retinal detachments were diagnosed within one month of injury, and Ross ${ }^{4}$ found $40 \%$ in a similar period.

The following study is of a series of patients who developed retinal breaks or retinal detachment after ocular contusion. Analysis of the results allows comment on: (1) the types of retinal breaks; (2) the time interval from injury to recognition of retinal detachment; (3) factors which limit visual recovery; (4) reason for delayed diagnosis of retinal detachment.

\section{Patients and methods}

The Retinal Clinic at the Royal Victoria Hospital, Belfast, is responsible for surgical treatment of all retinal detachments in Northern Ireland population 1.5 million. As most cases of ocular contusion are referred as emergencies to that hospital, we are in a position to record the early characteristics of most contusional retinal detachments. From January 1980 to December 1988 we treated 77 patients who developed retinal breaks or rhegmatogenous retinal detachment which were related to a definite episode of ocular contusion. This represents $6 \%$ of 1250 consecutive cases of rhegmatogenous retinal detachment treated within this period at Belfast.

\section{Results}

Of the 77 patients $49(63.6 \%)$ were seen at the Eye Clinic within 24 hours of injury and $64(83 \%)$ within six weeks. Fourteen (18\%) patients were seen for the first time more than six weeks after the injury. Sixty-nine $(90 \%)$ were male and eight $(10 \%)$ female. Their ages ranged from 5 to 69 years, mean $25 \cdot 1$ years. The majority of patients, $61(79 \%)$, were injured by missiles or during sports (Table 1). The latter group consisted of 23 patients of whom 11 were injured playing assiociation football and six from racquet sport accidents.

Of the 77 patients $65(84.4 \%)$ developed retinal detachment and $12(15 \cdot 6 \%)$ had flat retinal breaks. Simultaneous ocular injuries included vitreous haemorrhage in $\mathbf{4 0}$ patients $(52 \%)$ and hyphaema in $32(42 \%)$ patients (Table 2). 
The types of retinal breaks were grouped as dialyses at the ora serrata, irregular breaks within necrotic retina, horseshoe breaks, and giant tears (Table 3 ). Seven patients $(9 \%)$ were myopic, ranging from $-5 \cdot 5$ dioptres to -20 dioptres.

SURGICAL RESULTS AND VISUAL OUTCOME

All 77 patients were treated surgically, and of these cases $74(96 \cdot 1 \%)$ were successful. The postoperative visual recovery is summarised in Table 4, which shows that 36 patients $(46.8 \%)$ saw $6 / 9$ or better and $19(24 \cdot 7 \%)$ patients were $6 /$ 60 or worse. The causes of visual acuity of $6 / 60$ or worse are listed in Table 5. They include seven cases in which the poor vision could be directly attributed to posterior pole trauma, consisting of choroidal tears in five patients and macular holes in two patients.

INTERVAL FROM INJURY TO DIAGNOSIS OF RETINAL DETACHMENT

The patients were divided into three groups which were determined by the interval from injury to diagnosis of the retinal break or retinal detachment (Table 6).

\section{Group 1}

This group consisted of 24 patients who developed a recognisable retinal break or rhegmatogenous retinal detachment within 24 hours of injury (Table 7). Oral dialysis or necrotic impact

Table 4 Postoperative visual acuity

\begin{tabular}{lcl}
\hline & $N o$ & $\%$ \\
\hline $6 / 6-6 / 9$ & 36 & 47 \\
$6 / 12-6 / 18$ & 13 & 17 \\
$6 / 24-6 / 36$ & 9 & $11 \cdot 7$ \\
$6 / 60$ or less & 19 & $24 \cdot 7$ \\
Total & 77 & \\
\hline
\end{tabular}

Table 5 Causes of acuity $6 / 60$ or worse

\begin{tabular}{|c|c|c|c|}
\hline \multicolumn{3}{|c|}{$\begin{array}{l}\text { Choroidal tear } \\
\text { Macular pucker } \\
\text { Macular hole } \\
\text { Proliferative vitreopathy } \\
\text { Chronic retinal detchment preop } \\
\text { Amblyopia } \\
\text { Total }\end{array}$} & $\begin{array}{r}5 \\
2 \\
2 \\
3 \\
6 \\
1 \\
19\end{array}$ \\
\hline \multicolumn{4}{|c|}{$\begin{array}{l}\text { Table } 6 \text { Interval from injury to diagnosis of retinal break of } \\
\text { detachment }\end{array}$} \\
\hline Group & Interval & No & $\%$ \\
\hline $\begin{array}{l}1 \\
2 \\
3\end{array}$ & $\begin{array}{l}<1 \text { day } \\
1 \text { day-6 weeks } \\
6 \text { weeks-6 months } \\
6 \text { months-1 year } \\
>1 \text { year }\end{array}$ & $\begin{array}{r}24 \\
25 \\
18 \\
5 \\
5 \\
77\end{array}$ & $\begin{array}{r}31 \cdot 2 \\
32 \cdot 5 \\
23 \cdot 4 \\
6 \cdot 5 \\
6 \cdot 5\end{array}$ \\
\hline
\end{tabular}

Table 7 Types of retinal breaks and incidence of retinal detachment within one day of injury

\begin{tabular}{lcc}
\hline Type & No & Associated $R D$ \\
\hline Impact necrosis & 10 & 8 \\
Ora (dialysis) & 10 & 4 \\
Horseshoe & 2 & 0 \\
Giant tear & 2 & 2 \\
Total & 24 & 14 \\
\hline
\end{tabular}

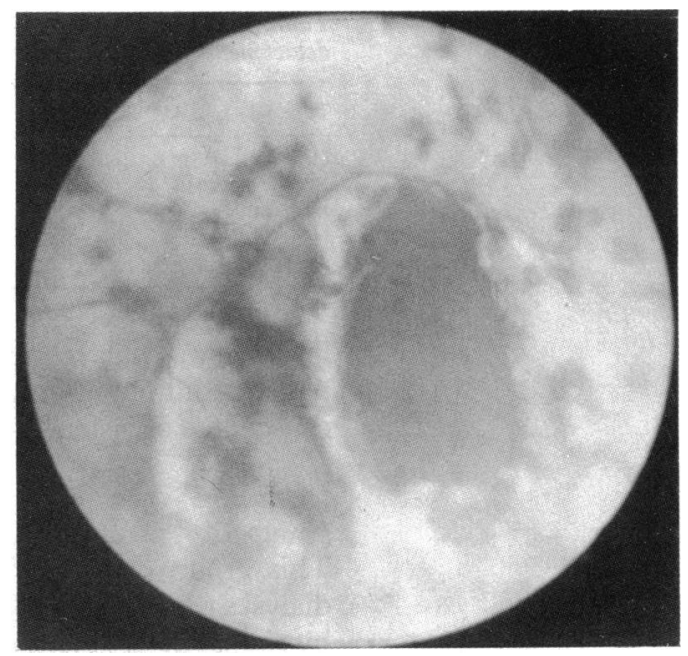

Figure 1: Inferotemporal fundus of left eye contains an oval retinal tear surrounded by oedematous and haemorrhagic retina, which is detached.

breaks accounted for the majority of breaks in this group, but it was noticeable that the necrotic type was more often associated with detachment. Fluorescein angiography was performed on a number of patients with necrotic breaks. This consistently showed non-perfusion of the oedematous retina round the break and profuse leakage of fluorescein through damaged retinal pigment epithelium into the subretinal space (Figs 1, 2).

\section{Group 2}

This group consisted of 25 patients who had a break or rhegmatogenous retinal detachment which was diagnosed between one day and six weeks after the injury (Table 8). Most of the breaks were oral dialyses which affected 13 (52\%) patients, of which 11 patients had retinal detachment and two had dialyses without detachment. The diagnosis of detachment or break was delayed in this group of patients for the following reasons: (1) vitreous haemorrhage prevented immediate postinjury examination of the peripheral retina in 10 patients; $(2)$ referral to

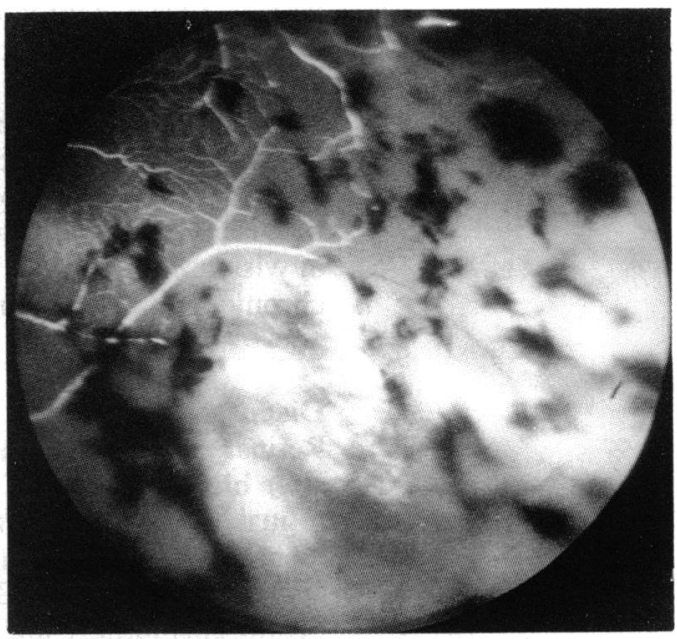

Figure 2: Fluorescein angiogram of fundus shown in Figure 1. There is gross retinal vascular stasis and ischaemia round the retina tear and leakge of dye from the choroidal vasculature beneath the tear. 
Table 8 Types of retinal break and incidence of retinal detachment one day to six weeks after injury

\begin{tabular}{lrc}
\hline Type & No & Associated RD \\
\hline Ora (dialysis) & 13 & 11 \\
Impact necrosis & 7 & 7 \\
Horseshoe & 4 & 4 \\
Giant tear & 1 & 1 \\
Total & 25 & 23 \\
\hline
\end{tabular}

hospital was delayed in seven patients; (3) nine patients did not attend until retinal detachment caused loss of vision.

Group 3

This group consisted of 28 patients with oral dialyses who presented with loss of vision caused by retinal detachment more than six weeks after the injury. The time interval from injury to diagnosis of retinal detachment ranged from two months to four years, mean 9.7 months. Of these 28 patients 15 were examined in the Eye Department within 24 hours of injury and the visual acuity was recorded. Vitreous haemorrhage was noted in 12 and hyphaema in 14 of these 15 eyes. However, retinal detachment was not diagnosed until the patient returned with visual loss caused by the detached retina. Delayed diagnosis of these 15 patients probably contributed to a permanently reduced acuity of more than three lines Snellen in 11 eyes which might otherwise have maintained normal vision. The presence of vitreous haemorrhage, hyphaema, and ocular discomfort had prevented immediate examination of the peripheral retina. These 15 patients were lost to follow-up until retinal detachment developed.

\section{VISUAL RECOVERY AND INJURY TO DIAGNOSIS} INTERVAL

Of the 24 patients (group 1) diagnosed within 24 hours of injury, $16(66 \%)$ regained $6 / 9$ vision or better and in four (16\%) the visual acuity was $6 /$ 60 or worse.

Group 2 consisted of 25 patients who were diagnosed from one day to six weeks after the injury. Of these, $17(68 \%)$ regained $6 / 9$ vision or better and in $5(20 \%)$ the visual acuity was $6 / 60$ or worse. Visual acuity of $6 / 60$ and worse was usually caused by direct macular injury in both group 1 and group 2.

The third group of 28 patients were diagnosed more than six weeks after injury, and of these, 5 $(18 \%)$ regained $6 / 9$ vision or better and in $9(32 \%)$ the visual acuity was $6 / 60$ or worse. Poor recovery of vision in group 3 patients was caused by chronic retinal detachment in every case.

\section{Discussion}

Retinal tears may occur in young healthy eyes after blunt injury. We treated 77 patients with retinal tear or rhegmatogenous retinal detachment which followed a documented episode of ocular contusion. In $63.6 \%$ of cases the retinal break, excluding giant tears, was found at the ora, which compares with an incidence of $59.4 \%$ reported by Cox et $a l^{2}$ but is more than the $53 \%$ observed by Goffstein and Burton. ${ }^{5}$ Cox et al did not report giant tears in their series of contusional retinal detachment, but Goffstein and Burton found a $16 \%$ incidence of these tears. We observed three (4\%) giant tears, and two of these were in myopic eyes of -16.0 and -20.0 dioptres, which supports the view ${ }^{5}$ that highly myopic eyes are at increased risk of giant tear formation following ocular contusion. We found that $57 \%$ of oral breaks affected the inferior temporal quadrant, which is the usual site of scleral impact. Cox et $a l^{2}$ observed that the inferior temporal quadrant was less often involved $(22 \%)$ and the upper nasal quadrant predominantly affected $(37 \cdot 8 \%)$. Seventeen eyes in our series contained irregular breaks within oedematous haemorrhagic retina at the point of scleral impact, which is usually the inferior temporal quadrant. Necrotic breaks were extensively described by $\mathrm{Cox}^{6}$ and represent impact retinal necrosis, which is a conscquence of direct concussional damage to the retina, and retinal vascular damage, which includes vasoconstriction and disintegration of capillary walls. ${ }^{7}$ Fluorescein angiography of these tears revealed striking retinal ischaemia and outpouring of fluid in the region of the tear. Gregor and Ryan ${ }^{8}$ and $\mathrm{Cox}^{6}$ showed experimentally that disruption of the retinal pigment epithelium occurs at the impact site immediately after blunt injury, and fluorescein angiography performed within 24 hours of injury in our cases confirmed profuse leakage through the damaged retinal pigment epithelium into the subretinal space. Development of retinal detachment within 24 hours of injury was a feature of necrotic retinal breaks in comparison with oral dialysis, and we suggest that leakage of fluid from the choroid into the subretinal space contributes to development of retinal detachment in addition to movement of vitreous fluid through the retinal break. Eight patients developed horseshoe tears at the site of pre-existing vitreoretinal degeneration as a consequence of sudden vitreous traction caused by deformation of the globe.

Classic laboratory experiments ${ }^{39}$ show that retinal breaks responsible for traumatic retinal detachment are formed at the time of injury. The observation is difficult to confirm clinically, as patients who develop traumatic retinal detachment rarely present for peripheral retinal examination immediately after the injury. For example Cox $e a^{2}$ reported that $12 \%$ of traumatic breaks or retinal detachments occurred immediately and $30 \%$ within one month of injury. Goffstein and Burton ${ }^{5}$ observed that $60 \%$ were diagnosed within eight months of injury. We were unable to confirm the experimental evidence and found that, although 49 patients were examined within 24 hours of injury, the retinal break or rhegmatogenous retinal detachment was recognised in only 24 eyes. In the remaining 25 patients diagnosis was unduly delayed for two reasons: (1) vitreous haemorrhage or hyphaema prevented early examination of the peripheral retina; and (2) 15 patients were not examined immediately after the injury by the retinal service and were lost to follow-up.

Analysis of the types of retinal breaks in our series shows that necrotic breaks, horseshoe breaks, and giant tears develop retinal detach- 
ment within six weeks of injury. Oral dialyses were more likely to be associated with delayed accumulation of subretinal fluid ${ }^{410}$ which spread slowly until the macular region was detached. ${ }^{7}$ If a retinal dialysis is unrecognised within six weeks of injury, these patients usually present with loss of vision within one year of injury, though a few present up to four years later.

Surgical reattachment of the retina was successful in $96 \%$ of eyes. The major causes of poor visual recovery were either chronic preoperative detachment of the macula or posterior pole contusional injury such as choroidal tear of lamellar hole at the macula. Patients diagnosed within six weeks of injury showed better visual recovery than those detected later, which reflects the more extensive retinal detachment associated with the latter cases. Overall, $47 \%$ of patients regained visual acuity of $6 / 9$ or better following surgery and $24 \cdot 7 \%$ were $6 / 60$ or worse. The visual recovery compares favourably with other reports, which found visual acuity of $6 / 60$ or worse in $32 \%$ of cases. ${ }^{411}$

Our experience emphasises the great importance of frequent and early examination of the retinal periphery after ocular trauma if vision is to be preserved. When vitreous haemorrhage or hyphaema obscures the view, the patient should be frequently re-examined until a complete view of the ora serrata is obtained.

I thank Mr C J F Maguire, Professor D B Archer, and Mr W C Logan, Ophthalmology Department, Royal Victoria Hospital, for their assistance, and Mrs Marie Loughran for typing the manuscript.

1 Eagling EM. Ocular damage after blunt trauma to the eye. $\mathrm{Br}$ f Ophthalmol 1974; 58: $126-40$.

2 Cox MS, Schepens CL, Freeman HM. Retinal detachment due to ocular contusion. Arch Ophthalmol 1966; 76: 678-85.

3 Delori F, Pomerantzeff O, Cox MS. Deformation of the globe under high speed impact: its relation to contusion injuries. Invest Ophthalmol Vis Sci 1969; 3: 290-301.

4 Ross WH. Traumatic retinal dialyses. Arch Ophthalmol 1981; 99: $1371-4$

5 Goffstein R, Burton TC. Differentiating traumatic from nontraumatic retinal detachment. Ophthalmology 1982; 89: 361-

6 Cox MS. Retinal breaks caused by blunt non-perforating trauma at the point of impact. Trans Am Ophthalmol Soc 1980; 78: 414-66.

7 Duke-Elder S. Concussions and contusions. System of ophthalmology. London: Kimpton, 1972: 14 (1): ch2 63-310.

8 Gregor Z, Ryan SJ. Blood-retinal barrier after blunt trauma to the eye. Graefes Arch Clin Exp Ophthalmol 1982; 219: 205-8. 9 Wiedenthal DT, Schepens CL. Peripheral fundus changes associated with ocular contusion. Am f Ophthalmol 1966; 62: 465-77.

10 Hagler WS, North AW. Retinal dialysis and retinal detachment. Arch Ophthalmol 1968; 79: 376-88.

11 Tasman W. Retinal dialysis following blunt trauma. In Freeman HM, ed Ocular trauma. New York: AppletonCentury-Crofts, 1979; 295-9. 